\title{
The development of a novel biofeedback system for the evaluation, recording, control and correction of the spinal posture Elias Kallistratos*1, Vassilis Mahairas ${ }^{3}$, Maria Papadopoulou ${ }^{3}$ and Themistoklis Parintas ${ }^{2}$
}

\author{
Address: ${ }^{1}$ Clinical Practice Laboratory, Physiotherapy Department, Alexander Technological Educational Institute of Thessaloniki, Greece, \\ ${ }^{2}$ Training Department, Power Public Corporation S.A., Greece and ${ }^{3}$ R \& D Dept. Microforce Electronic, Greece \\ * Corresponding author
}

from $5^{\text {th }}$ International Conference on Conservative Management of Spinal Deformities

Athens, Greece. 3-5 April 2008

Published: 15 January 2009

Scoliosis 2009, 4(Suppl I):O25 doi:I0.I I86/I748-7I6I-4-SI-O25

This abstract is available from: http://www.scoliosisjournal.com/content/4/SI/O25

(c) 2009 Kallistratos et al; licensee BioMed Central Ltd.

\section{Aim}

The goal of this study was to develop a system which controls and records the posture and the spinal curvature for both diagnostic and therapeutic use.

\section{Background}

The system consists of a sensor PCB $(60 \times 40 \mathrm{~mm}, 50 \mathrm{~g})$ that is placed at the back of the patient, using an adhesive material. Biomechanical analysis (BMA) of the spine with the Spinalmouse ${ }^{\circledast}$ system was formerly used to show the abnormal levels of the spine and indicate the sensor's placement. The practitioner sets the neutral position (or reference position) and can monitor and record the patient's spinal posture in real time, for 12 continuous hours. The data is also stored in the sensor's memory and can be downloaded to a PC. The flexion and extension, as well as the lateral bending limits are set and an audio signal or a low electric stimulus, (feedback) warns the patient when he/she reaches them. How many times and how long the patient remained beyond the preset limits is also recorded.

\section{Patient population}

To evaluate our system, 40 subjects (aged: $20 \pm 5.4$ y) with abnormal spine curves, participated in our study.

\section{Results}

The BMA of the participants, before and after a 4 hours' session, showed a significant $(\mathrm{p}<0.05)$ improvement of their posture. The participants gave $8 \pm 2.3$ (max: 10 scale) score in their gratification.

\section{Conclusion}

The system successfully works as an advanced biofeedback therapy method that enhances self-correction of the undesirable posture and as a diagnostic tool.

\section{References}

I. Wong MS, Mak AF, Luk KD, Evans JH, Brown B: Effectiveness of audio-biofeedback in postural training for adolescent idiopathic scoliosis patients. Prosthet Orthot Int 200I, 25(I):60-70.

2. Metherall P, Dymond EA, Gravill N: Posture control using electrical stimulation biofeedback: a pilot study. J Med Eng Technol 1996, 20(2):53-9.

3. Maki H, Yonczawa $\mathrm{Y}$, Ogawa $\mathrm{H}$, Sato $\mathrm{H}, \mathrm{Hahn} A W$, Caldwell WM: A welfare facility resident care support system. Biomed Sci Instrum 2004, 40:480-3. 